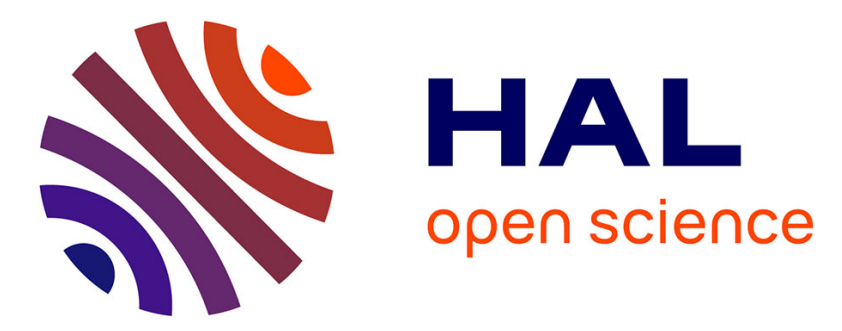

\title{
Ecology of the meadow spittlebug Philaenus spumarius in the Ajaccio region (Corsica) -I: Spring
}

\author{
Jérôme Albre, José María García Carrasco, Marc Gibernau
}

\section{To cite this version:}

Jérôme Albre, José María García Carrasco, Marc Gibernau. Ecology of the meadow spittlebug Philaenus spumarius in the Ajaccio region (Corsica) -I: Spring. Bulletin of Entomological Research, 2021, pp.1-11. 10.1017/S0007485320000711 . hal-03116101

\section{HAL Id: hal-03116101 \\ https://hal.science/hal-03116101}

Submitted on 20 Jan 2021

HAL is a multi-disciplinary open access archive for the deposit and dissemination of scientific research documents, whether they are published or not. The documents may come from teaching and research institutions in France or abroad, or from public or private research centers.
L'archive ouverte pluridisciplinaire HAL, est destinée au dépôt et à la diffusion de documents scientifiques de niveau recherche, publiés ou non, émanant des établissements d'enseignement et de recherche français ou étrangers, des laboratoires publics ou privés. 
3 Ecology of the meadow spittlebug Philaenus spumarius in the Ajaccio region

4 (Corsica) - I: Spring

6 Jérôme Albre ${ }^{1, *}$, José María García Carrasco ${ }^{2}$ and Marc Gibernau ${ }^{1}$

$7{ }^{1}$ University of Corsica Pascal Paoli-CNRS, UMR 6134 SPE, Equipe Chimie et Biomasse, 8 Route des Sanguinaires, 20000 Ajaccio, France.

$9{ }^{2}$ Universidad de Málaga, Department of Animal Biology, Faculty of Science, E-29071, 10 Malaga, Spain.

Short title: Ecology of Philaenus spumarius in Corsica

Corresponding author: Jérôme Albre, University of Corsica Pascal Paoli-CNRS, UMR 6134 SPE, Equipe Chimie et Biomasse, Route des Sanguinaires, 20000 Ajaccio, France. E-mail: albre_j@univ-corse.fr

17 Abstract: The meadow spittlebug, Philaenus spumarius (L.) (Hemiptera: Aphrophoridae), is the main vector in Europe of the recently detected plant pathogen bacterium Xylella fastidiosa Wells et al. (Xanthomonadales: Xanthomonadaceae). While the ecology of continental populations is well documented, nothing is known about the insular populations of $P$.

21 spumarius, such as in Corsica, where the bacterium was detected in 2015. Hence, in an epidemiological context, the ecology of $P$. spumarius has been studied in a maquis landscape in the Ajaccio region between 2017 and 2019. Adults and nymphs were almost exclusively

24 collected on Cistus monspeliensis L. (Cistaceae). However, very few specimens were collected 
25 in summer, suggesting a movement of the adults to sheltered habitats. Unfortunately, despite 26 several trapping methods used, the location adult summer habitat remains unknown for the 27 studied population. It might be tempting to destroy the central plant host of $P$. spumarius 28 populations. However, as spittlebug nymphs are highly polyphagous on low-growing plant 29 species and as the females can lay eggs in any dead plant tissues, such practice could have a 30 limited the impact. Instead, the strong relationship between $P$. spumarius and C. monspeliensis 31 could be used to monitor spittlebug populations, to limit/concentrate the means of insect 32 control, or in an agronomic context to lure insects away from crops. Maintaining natural 33 arboreal vegetation around agronomic systems could help decrease insect abundance - and 34 potentially, pathogen load - on cultivated species. Such hypotheses need to be further studied 35 by landscape experiments.

37 Key words: host plant diversity; host plant palatability; Cistus monspeliensis; summer habitat; 38 sex ratio; nymphs behaviour 


\section{Introduction}

The Aphrophoridae (Hemiptera) is a relatively poorly diversified family, with about 900 described species worldwide, most of them inhabiting tropical regions (Richards \& Davies, 1977; Shih \& Yang, 2002). In Europe, this family is represented by about 29 species (Jach, 2013), of which only six are present in Corsica (Chauvel et al., 2015; Albre \& Gibernau, 2019). The meadow spittlebug, Philaenus spumarius (L.), is the most widespread species and can be found in the whole Palearctic region from Western Europe to Russia. The ecological plasticity of $P$. spumarius has enabled the spittlebug to be successful in various non-native regions such as Japan, North America (USA, Canada), Hawaii and New Zealand (Yurtsever, 2000b). It harbours such extremely variable dorsal colours and patterns that up to 16 phenotypes have been described. The genetic basis of this phenotypic diversity was thus intensively studied and relationships with several ecological constraints (climatic conditions, predation, or habitat composition) were found (Halkka et al., 1973; Stewart \& Lees, 1988; Yurtsever, 2000a; Rodrigues et al., 2016; Borges et al., 2018). In Europe, P. spumarius is actually studied mainly for hosting the Latin American bacterium Xylella fastidiosa Wells et al., which was detected for the first time in Southern Italy (Salento, Puglia region) in 2013 (EPPO, 2013). Since then, this bacterial phytopathogen has been responsible for the death of thousands of olive and almond trees in the western Mediterranean region. In Italy, olive growers have already lost between 0.2 and 0.6 billion Euros in investments and, according to the different economic model, the premature death of the olive trees could cost between 1.9 and 5.2 billion Euros over the next 50 years if no resistant trees are developed (Schneider et al., 2020). With hundreds of host plants recorded worldwide, $X$. fastidiosa is considered as a major threat for European flora (EFSA, 2018). While initially introduced via infected ornamental trees (e.g. coffee trees), it has been demonstrated that $P$. spumarius was the main vector of the bacterium in Europe, propagating efficiently the bacterium to a wide diversity of native, ornamental and cultivated 
plant species (Saponari et al., 2014; Cornara et al., 2017). The ecology of $P$. spumarius has thus been intensively studied in this epidemiological context, particularly in European continental populations developing in cultivated areas. The adults can be observed from the end of spring, after the last molt, to the end of autumn (Yurtsever, 2000b). However, in some populations, adults find refuge in cool habitats, usually in the shady and humid foliage of the surrounding shrubs and trees. This behavior mainly concerns populations subjected to (extreme) drought and warm conditions, most often in the southernmost parts of the distribution area (Drosopoulos \& Asche, 1991; Drosopoulos et al., 2010). This sheltering phase, where it exists, ends at the end of summer - early autumn. Egg laying, induced by the daylight shortening and lower temperatures (Stewart \& Lees, 1988), occurs in autumn on plants of the lower vegetation layers (herbaceous and small shrubs). Females can produce between 350-400 eggs, in clutches of up to 20 eggs aggregated in a cement-like secretion. Eggs are laid either directly on suitable host plants, or on dead plant tissues (Yurtsever, 2000b). The eggs of $P$. spumarius hatch in early spring after an overwintering period (Nickel \& Remane, 2002). Nymphs produce a characteristic spittle mass on the leaves or on the twigs of the plants inside which they are protected against predators and desiccation. Highly polyphagous, nymphs consume xylem sap and can develop on almost any available plant, with a preference for the youngest tissues of herbaceous plants and small shrubs. When mature at the end of spring, they set up a cavity in the spittle mass in which they molt into imagoes. As with the nymphs, adults are highly polyphagous, with hundreds of host plants recorded worldwide, belonging to a wide diversity of families from grasses to trees, including conifers (Yurtsever, 2000b; EFSA, 2018).

While $P$. spumarius is present in the whole Mediterranean region including the islands, such as Corsica, Sicily, Sardinia, the Balearic Islands and Crete, defined ecological parameters are almost exclusively based on continental populations developing in agricultural landscapes (Yurtsever, 2000b; Cornara et al., 2018; Morente et al., 2018; Bodino et al., 2019; Dongiovanni 
90

91

et al., 2019). However, field surveys in Corsica highlighted that the adults of P. spumarius collected were found almost exclusively on a single plant species - Cistus monspeliensis L. which is an unusual observation for this highly polyphagous species (Chauvel et al., 2015; Cruaud et al., 2018). In order to contribute to the knowledge of the epidemiology of $X$. fastidiosa, we studied the ecology and biology of the meadow spittlebug in a non-agricultural maquis habitat with weak anthropogenic perturbations. We present original data on one insular population of $P$. spumarius from South-West of Corsica near Ajaccio. The abundance and temporal variation of this spittlebug species was studied as well as the host plant diversity and palatability for the nymphs during their ontogenesis. Finally, the mobility of the adults among vegetation strata was studied during emergence, using different trapping experiments. Our specific questions were: (1) is $P$. spumarius specialized on $C$. monspeliensis as suggested by previous field surveys (Chauvel et al., 2015; Cruaud et al., 2018)?; (2) does the plant-host specialization, if any, concern adults and/or nymphs?; and (3) does $P$. spumarius find refuge in a sheltered habitat during summer since Corsica, beside been an island, belongs to the southern range of its distribution?

\section{Materials and methods}

\section{Survey}

The studied site is located near the University campus outside of Ajaccio (GPS coordinates: $41.913492 \mathrm{~N}, 8.655433 \mathrm{E})$. The habitat is a typical thermomediterranean shrubby vegetation (i.e. maquis) dominated by Pistacia lentiscus L. (Anacardiaceae), Cytisus laniger (Desf.) DC. (Fabaceae) and Cistus monspeliensis with sparse trees Olea europaea L. (Oleaceae) and Arbutus unedo L. (Ericaceae) and weak anthropogenic perturbations during the past 35 years. A 34-month-long survey (from March 2017 to December 2019) was conducted in $~ 1100 \mathrm{~m}^{2}$ maquis habitat to record the temporal population pattern of adults of Philaenus spumarius. 
115 Simultaneously, the Auchenorrhyncha fauna present in the locality, belonging mainly to the

116 Cicadellidae and Issidae families, were collected. Every 2-3 weeks, insects present in the low 117 (under $120 \mathrm{~cm}$ ) and high (above $120 \mathrm{~cm}$ ) vegetation strata were separately collected using a 118 sweep-net; a 20 minutes sampling was conducted in both strata. In total, 54 insect samples were 119 collected for each vegetation stratum. At our studied site, the low vegetation stratum 120 corresponded to the herbaceous and shrub species such as Cistus monspeliensis, C. creticus L.

121 (Cistaceae) and Myrtus communis L. (Myrtaceae). The high vegetation stratum corresponded to trees mainly Olea europaea, Arbutus unedo, Pistacia lentiscus and Phillyrea L. spp. (Oleaceae). All the insects were identified and sexed by examining their genitalia under

124 dissecting microscope (Albre \& Gibernau, 2019).

\section{Adult ecology and behaviour}

Different experiments were performed soon after the emergence of $P$. spumarius adults, during

the period when extremely few specimens were collected using the sweet-net approach. In order to verify whether the adults of $P$. spumarius took refuge in the tree foliage, intensive sweep-net captures were thus performed up to 6 meters high in 10 trees for each main species of the studied area, Olea europaea, Arbutus unedo and Pistacia lentiscus.

Interception traps were also used in order to passively capture the adults during the same period

133 (soon after their emergence) and to study their mobility. We thus placed 54 yellow sticky traps

$134(25 \times 11 \mathrm{~cm})$ in the low vegetation stratum, including grasses, Cytisus laniger, C. monspeliensis 135 and Myrtus communis and in the high vegetation stratum, including Arbutus unedo, olive trees,

136 Pistacia lentiscus and Phillyrea sp., close by or in the foliage of each species. The experiment 137 was performed from May 25 to June 28, 2018, i.e. soon after adults emerged in our study site, 138 when adult movements were more likely. Traps were checked every 3 days, and the insects 139 identified and counted, using stereo microscope when necessary. 
140 In order to verify whether adults were looking for shady and humid habitats to survive the

141 summer conditions, we constructed shelters consisting of two green overlaid sticky plates of

142 cardboard separated by $2 \mathrm{~cm}$; a recipient filled with water was placed between the plates. This

143 artificial system was supposed to represent a shaded and relatively humid (micro-)habitat as the

144 natural reported shelter required for the survival of $P$. spumarius in summer.

145 The nymphs of $P$. spumarius produce conspicuous self-generated white foam nests in which

146 they obligatory develop, from early February to the end of April. As neonate nymphs are

147 relatively immobile, it has been considered that these foams could constitute a proxy to identify

148 the females' choice for egg laying. We thus recorded the presence or absence of foams on all

149 the plants of the studied area in early spring. In order to understand the progression of the foam

150 distribution in the habitat throughout the season, foam presence or absence and the number of

151 foams per plant were recorded along a $100 \mathrm{~m}$ long transect from March $9^{\text {th }}$, when most of the

152 foams were visible, through April $24^{\text {th }}$, before the emergence of the adults. The range of

153 movement exhibited by medium to full-sized nymphs was estimated by placing nymphs on a

154 flat surface covered with paper. Fully exposed and deprived of food, nymphs searched for a

155 plant and released some humidity on the paper, allowing us to follow their (sinuous) tracks.

156 This experiment was repeated with 73 nymphs (body size range: $2.86-5.98 \mathrm{~mm}$ ) and movement 157 was tracked for 20 minutes trials.

\section{Nymph behaviour and survival}

160 Once per week from March $15^{\text {th }}$ to May $3^{\text {rd }}, 2017$, which was near the end of the season during

161 which foams were present in our studied site, 13 foams from the same area were sampled 162 randomly. All the nymphs contained within the foams were counted and their body length 163 measured using a stereo microscope. 
164 In order to verify the polyphagy of the nymphs of $P$. spumarius, development experiments were

165 performed by bagging the foliage of different plant species in the presence of natural foams or 166 by transferring single neonate nymphs (all collected on $C$. monspeliensis) on a suite of the

167 aforementioned plant species. Success was considered when the nymph completed its 168 developmental cycle into an adult.

169

4. Data analyses

171 Survey

172 The abundances of $P$. spumarius in the vegetation strata were studied by comparing the number

173 of individuals captured in low or high plants (Chi square test). Temporal variations of the

174 number of adults (male or female) or the sample sex ratios were tested by fitting linear

175 regressions. The mean sex ratio of the samples were also compared among seasons with a non 176 parametric test (Kruskall-Wallis).

$177 \quad$ Nymphs

178 The temporal variations of nymph number or size per foam in natural conditions were tested

179 with linear regressions. The nymph travelled distance in laboratory conditions were also tested

180 for linear relationship with their size.

181 All statistical analyses were performed with the statistical software Past 4.02 (Hammer et al., 182 2001).

183

184 Hammer, Ø., Harper, D.A.T., Ryan, P.D. (2001) PAST: Paleontological statistics software 185 package for education and data analysis. Palaeontologia Electronica 4(1): 9pp. http://palaeo186 electronica.org/2001_1/past/issue1_01.htm

\section{Results}




\section{Survey}

\section{a. Relative abundances}

Among the 1848 Auchenorrhyncha specimens collected during the survey (fig. 1), the Aphrophoridae Philaenus spumarius was the most abundant species $(\mathrm{n}=653 ; 35 \%)$, followed by the Cicadellidae Euscelis lineolata Brulle $(\mathrm{n}=442 ; 24 \%)$ and the Issidae Latilica maculipes (Melichar) $(\mathrm{n}=164 ; 9 \%)$. The only other known potential vector of the bacterium Xylella fastidiosa in the studied area was the species Neophilaenus campestris (Fallén) (Aphrophoridae), which accounted for only $1 \%(n=10)$ of the total collected specimens. The total diversity list of Auchenorrhyncha present in the studied site represented 37 species including three alien species for Europe (Albre \& Gibernau, 2019).

\section{b. Temporal pattern of Philaenus spumarius population}

An annual pattern was observed, with 2 main peaks of adult abundances: in spring, from late April to the end of June, and in autumn, from early October to the end of November (fig. 2, green bars). The second peak abundance was the most important one in terms of number of insects collected, representing $72 \%, 79 \%$ and $75 \%$ of the specimens collected in 2017,2018 and 2019, respectively. Thereafter, the number of adults reduced during the survey (range: 0-3 individual(s) captured) in summer and increased massively only in autumn.

The annual temporal pattern of $P$. spumarius appeared to be different from the mean Auchenorrhyncha pattern (fig. 2, blue shaded curve). In spring, P. spumarius and the other Auchenorrhyncha species presented a peak of abundance. On the contrary in autumn, $P$. spumarius presented its maximum abundance, while the Auchenorrhyncha community is strongly decreasing or at its minimum abundance.

(1)


214 Overall, the adults of $P$. spumarius were far more abundant in the low vegetation stratum than 215 in the high one, as up to $90.5 \%(\mathrm{n}=591)$ of specimens were collected from low-level vegetation 216 (table 1). This habitat preference was even more important between July and December, with 217 more than $96.6 \%$ of the insects being collected on low plants $(<120 \mathrm{~cm})$ during all three years 218 of the survey. Interestingly, the insect's low vegetation tendency was less pronounced between 219 January and June when $76.7 \%$ and $74.4 \%$ of the adults of $P$. spumarius were collected on low 220 plants in 2018 and 2019, respectively. No significant difference was found in the number of 221 adults of $P$. spumarius captured between January and June 2017 on low and high plants $\left(\mathrm{Chi}^{2}{ }_{1}\right.$ $222=0.05, p=0.83)$. It is also important to note that in the low vegetation stratum of the studied 223 area, the insects were almost exclusively collected on plants of Cistus monspeliensis.

\section{d. Sex-Ratio}

227 The number of males and females were strongly positively related (fig. $3 ; \mathrm{R}^{2}=0.86, \mathrm{p}=3.7 \mathrm{x}$ $22810^{-4}$ ), and there was no major sex ratio bias (line slope not different from one, $\mathrm{F}_{1,105}=0.11, \mathrm{p}=$ 229 0.74). The only sample with a significant biased sex ratio was on November $22^{\text {th }} 2018$ with 21 230 males and 40 females $\left(\mathrm{Chi}^{2}{ }_{1}=6.03, \mathrm{p}=0.014\right)$.

231 There was a strong seasonal effect on sex ratio (fig. 4) independent of sample sizes and despite 232 large variation (Kruskal-Wallis: $\left.\mathrm{H}\left(\mathrm{Chi}^{2}\right)=12.6, \mathrm{p}=0.005\right)$ with winter and summer periods 233 presenting significantly lower male proportions $(13.3 \pm 23.1 \%$ and $19.8 \pm 28.6 \%$ respectively $)$ 234 than during the spring and autumn periods (57.6 $\pm 25.8 \%$ and $52.7 \pm 13.8 \%$ respectively).

\section{a. Summer adult habitat}


238 Only 3 adults of $P$. spumarius were collected during all the summer using the different trap 239 systems specifically designed, suggesting they were not adapted (table 2). Sweep-net captures 240 at about $6 \mathrm{~m}$ high in the foliage of the 30 trees present in the vicinity of the surveyed area resulted 241 in 217 insects, most of them (95.4\%) belonging to the Cicadellidae family. Only 3 adult 242 specimens of $P$. spumarius were collected on Arbutus unedo $(\mathrm{n}=2)$ and olive tree $(\mathrm{n}=1)$. 243 Similarly, the yellow sticky traps placed in the surveyed site, both in the trees and in the low 244 vegetation, trapped mainly Cicadellidae specimens $(\mathrm{n}=252 ; 99.2 \%)$; no P. spumarius was 245 trapped. Finally, only 1 insect (Cicadellidae) was collected in the shaded sticky shelters, 246 suggesting the latter were not well-adapted to attract Auchenorrhyncha.

\section{b. Host plants diversity for foams}

249 Our survey was performed during the early ontogenesis of $P$. spumarius (e.g. small sized foams) when neonate nymphs were hardly mobile. Hence, we hypothesised that the foam distribution reflected female host choice for oviposition. Among the 3672 plants included in our survey that belonged to 37 species, we recorded foams in 977 individual plants and 10 different plant species (fig. 5). However, most of the foams were observed on two Cistaceae species, namely C. monspeliensis (93.2\%) and C. creticus (3.3\%). A few foams were also observed on Asteraceae (Dittrichia viscosa (L.) Greuter, Urospermum dalechampii (L.) Scop. ex F.W. unedo). It is worth noting that foams were only present on P. lentiscus and A. unedo when 259 foliage contacted with leaves of $C$. monspeliensis harbouring foams.

260 Moreover, up to $52 \%$ of the C. monspeliensis (1737 plants observed) and $13 \%$ of the C. creticus 261 (246 plants observed) specimens were observed to harbour at least one foam (fig. 5). Foams 
262

263

264

265

266

267

were also recorded on $40 \%$ of the Urospermum dalechampii (Asteraceae) specimens, but only 15 individuals were observed in the studied area.

\section{Nymphs}

\section{a. Foam density}

While in early March all of the observed foams were exclusively found on C. monspeliensis, this proportion decreased at the end of April (86\%), with foams also appearing on C. creticus, Dittrichia viscosa and on other plant species (table 3a). Interestingly, this decrease of the proportion of foams on $C$. monspeliensis was accompanied by an increase of the proportion of C. monspeliensis plants (51\%) hosting at least one foam (table $3 \mathrm{~b}$ ).

\section{b. Nymphal development}

During the first month of spring, the body size of the nymphs increased regularly from $2.3 \mathrm{~mm}$ to about $5.3 \mathrm{~mm}$, but then remained relatively constant over the last month of development (fig. 6 - blue curve). We were not able to correlate body size differences with the different known nymphal instars of $P$. spumarius.

The number of nymphs per foam appeared to be significantly negatively correlated with the size of the nymphs $\left(R^{2}=0.62, \mathrm{P}=0.020\right.$; fig. 6 - orange curve $)$, with $1.86 \pm 1.35$ neonate nymphs per foam in mid-March and $1.08 \pm 0.86$ nymph per foam in early May. Up to 6 nymphs were found in the same foam in one occasion.

\section{c. Nymphs capacity movement}

When removed from their foam and deposited on a flat paper surface, nymphs walked an average of $38.5 \mathrm{~cm}$ in 20 minutes; the maximum distance travelled was $89 \mathrm{~cm}$ (fig. 7). No relationship was found between the nymph size of the nymphs and the distance travelled $\left(\mathrm{R}^{2}=\right.$ 
0.022). The distribution of distances travelled is clearly not unimodal, but instead seems multimodal, with many spittlebugs travelling either short or relatively longer distances (fig. 7).

\section{d. Host plants of the nymphs}

In total, 158 neonate nymphs were individually collected from $C$. monspeliensis and manually transferred to and bagged on one of 15 common plant species at the studied site (table 4). The manual depositions of nymphs on the Cistaceae $C$. monspeliensis, the main natural host plant of $P$. spumarius in Corsica, but also on C. creticus resulted in $100 \%$ full development into adults. Hence, it can be considered that manual depositions had an insignificant effect on the survival and development of the nymphs; and that observed survival differences were likely due to differences in host plant palatability rather than to experimental effects. Asteraceae species also appeared to be average to excellent host species for nymphs of $P$. spumarius, with success rates ranging from $54 \%$ to $100 \%$ according to the species (table 4 ). On the other hand, Plantago L. species (Plantaginaceae) and Cytisus laniger appeared not to be very suitable host species with only $33-50 \%$ of the nymphs completing their development. Similarly, the strawberry tree, Arbutus unedo (Ericaceae), was also not a good host plant with only $10 \%$ of nymphal developmental success. At last, it was not possible to obtain any adult from nymphs on the other tested trees Pistacia lentiscus and Olea europaea or the perennial herb Asphodelus ramosus L. (Asphodelaceae). 
307

308

309

310

\section{Discussion}

\section{Survey}

A survey of the Auchenorrhyncha fauna was performed over 3 consecutive years in a maquis landscape of the Ajaccio region of Corsica. Our main focus was on the Cicadellidae, Aphrophoridae, Issidae and Tettigometridae families. A total of 1848 adult specimens belonging to 32 species was recorded (Albre \& Gibernau, 2019). The Cicadellidae was the most diversified family (27 species) and accounted for $50.1 \%$ of the Auchenorrhyncha fauna, with Euscelis lineolata the most represented Cicadellidae species (47.7\% of the specimens). While poorly diversified (3 species), it appeared that the Aphrophoridae represented $35.9 \%$ of the collected insects and was almost exclusively represented by one species, Philaenus spumarius (98.5\% of the Aphrophoridae). The Issidae (4 species and $11.1 \%$ of the collected insects) was mainly represented by Latilica maculipes ( $79.6 \%$ of the Issidae). Finally, with only $2.9 \%$ of the collected insects and 3 species, the Tettigometridae was the least represented family in the Ajaccio region (Albre \& Gibernau, 2019).

A cyclic pattern of abundances was observed over the three years of survey, with a general peak of abundances from early April to the end of May, corresponding to the general plant blooming in spring, leaving few active insects into summer (July and August), which are the warmest and driest weeks of the year. In autumn, from early October to the end of November, P. spumarius "reappeared" in high abundances in the surveys and created a second peak, much more important than the first one and accounting for $61-81 \%$ of the total Auchenorrhyncha community in the habitat. However, the vertical distribution of $P$. spumarius in the vegetation differed according to the season. While $51.2-76.7 \%$ of the individuals were collected in the lower stratum in the spring, low vegetation contained $96.6-97.3 \%$ of all $P$. spumarius throughout the autumn peak. This habitat preference suggests that at the end of May / early June, the young adults left their nymphal habitat, corresponding to the lower stratum of the 
332

333

vegetation $(<120 \mathrm{~cm}$, cf later), and disappeared from the vegetation till the end of September. Then, adults reappeared in the lower vegetation and could be observed in high numbers till the end of November. The transitional phases, i.e. the disappearance from and the return to the lower stratum, were rapid phenomena (less than 2 weeks), making it difficult to determine in what type of habitat the adults spend the summer period. A similar pattern of abundances has already been recorded for $P$. spumarius in different parts of its distribution range, particularly in the southernmost areas. In summer, adults were often captured in shrubs and trees in Italy, Greece, Spain or Turkey, but most often in low numbers (Yurtsever, 2001; Drosopoulos, 2003; Cornara et al., 2017; Morente et al., 2018).

The sex ratio with even males: females remained relatively constant in all samples throughout the year (fig. 3), which is consistent with the literature (Bodino et al., 2019). Only one sample had a significantly biased sex ratio, 40 females to 21 males, on November $22^{\text {th }}$; interestingly this date corresponded to the period when the annual adult cycle of $P$. spumarius ended (fig. 2). When pooling the capture samples per season, a significant sex ratio difference was observed (fig. 4). In winter (January-March) and summer (July-September) four times more females were captured than males, suggesting a phenological and/or survival difference based on gender. On the contrary in spring (April-June) and autumn (October-December) the sex ratio was balanced.

\section{Summer adult habitat}

Despite intensive surveys and experiments, it was almost impossible to find any adult in Corsica in the summer, where both nymphs and freshly-emerged adults were present in high densities the previous spring. The drastic diminution of the adults from the ground vegetation in summer, common in the Mediterranean region, is considered to be a consequence of the extreme dry and warm conditions of the region (Cornara et al., 2017; Morente et al., 2018; Bodino et al., 2019; Santoiemma et al., 2019). As the summer goes on, the spring host plants of P. spumarius (both 
nymphs and young adults) dry out or are severely water-stressed. It is possible that these plants are no longer suitable for consumption. In the continental USA, where conditions in summer are less extreme, it has been shown that the turgor decrease of the host plants, or their disappearance, lead to a migration of adults to more turgid plants present in the close vicinity (Weaver \& King, 1954). In the Mediterranean region, and particularly in Corsica, most of the plants from the low stratum are dried out in summer and probably not enough turgid for an easy xylem sap consumption, and thus adults need to move farther and/or to exploit new habitats. In some parts of the Iberian Peninsula (Morente et al., 2018) or in the Liguria region (Bodino et al., 2019), insects can migrate vertically towards the neighbouring trees during the summer season. Several Philaenus species are also known to find refuge in the neighbouring trees (Quercus ilex L., Q. suber L.) and shrubs in the Mediterranean part of their distribution area (Drosopoulos, 2003; Drosopoulos et al., 2010). However, in our surveys, it was not possible to find adults on trees present in the vicinity, suggesting migrations out of the studied zone over relatively longer distances. One possibility is that adults could migrate to some water streams present in the neighbouring valleys, as observed in Central Spain (Morente et al., 2018), or towards the sheltered northern slopes of the relief. In such relatively humid habitats, plants, including low stratum species, remain turgid throughout the summer and thus could be used as food plants by adults. Populations could also migrate to higher altitudes or far to the north, where turgid species can be found even in summer (Drosopoulos, 2003). However, $P$. spumarius are not good flyers and, unless carried by the wind, cannot fly over long distances by themselves (Weaver \& King, 1954), suggesting long northward migrations improbable. For our study, we were not able to find the summer habitat of $P$. spumarius in the maquis vegetation near Ajaccio.

For some authors, the meadow spittlebug survives the extreme summer conditions by aestivating in a sheltered habitat (Drosopoulos, 2003; Drosopoulos et al., 2010; Chauvel et al., 
382

383

384

2015). However, by definition, aestivation, or summer dormancy, is a survival strategy to sustain lack of food or any extreme conditions (such as temperatures, desiccation) during which the animal is inactive and stops feeding (Masaki, 2009; Richard, 2009; Wang et al., 2015). From our observations, adults did not survive more than $24 \mathrm{~h}$ without feeding (Albre, per. obsv.) suggesting that $P$. spumarius might not be able to aestivate as mentioned in several works (Drosopoulos, 2003; Drosopoulos et al., 2010; Chauvel et al., 2015). Further studies on the summer adult strategy to survive the dry season are needed to assess whether $P$. spumarius aestivates or not in Corsica.

In the Ajaccio region, most of the foams were observed on Cistus monspeliensis (93.2\%); foams were also recorded on C. creticus (3.3\%) and Dittrichia viscosa (1.3\%). Moreover, $52 \%$ of the 1737 C. monspeliensis, $13 \%$ of the 246 C. creticus and $6 \%$ of the 221 D. viscosa plants hosted at least one foam. Up to $40 \%$ of the Asteraceae Urospermum dalechampii also hosted foam; however only 15 individuals were found in the studied area. The predominance of foams on $C$. monspeliensis confirms previous observations recorded in recent years for the Corsican populations of P. spumarius (Cruaud et al., 2018; Albre \& Gibernau, 2019). However, such a strong host plant bias is in total contradiction with the literature. $P$. spumarius is described as highly polyphagous, with nymphs developing mainly on Asteraceae species. The species' polyphagy is considered as a key factor explaining the large distribution range of the species, native from the Palaearctic region, and its success when introduced in foreign territories, such as New Zealand, Hawaii or Japan. Comparatively, the nymphs of numerous Philaenus species are oligophagous on arid vegetation ( $P$. arslani Abdul-Nour \& Lahoud and P. loukasi Drosopoulos \& Asche) or monophagous on Asphodelus microcarpus (P. signatus Melichar, P. italosignus Drosopoulos \& Remane, P. tarifa Remane \& Drosopoulos and P. maghresignus Drosopoulos \& Remane), and present more reduced distribution areas (Drosopoulos et al., 
407

408

2010). The manual transfer of neonate nymphs collected on field $C$. monspeliensis resulted in $100 \%$ full development into adults when deposited on plant of the same species, suggesting such handling had an insignificant effect on the survival and development of the nymphs. The manual deposition experiments clearly demonstrated that they could achieve their development on most of the Asteraceae tested (54 to 100\%), on C. creticus (100\%), on C. laniger (Fabaceae; 54\%) and on Plantago spp. (Plantaginaceae; 33 to 50\%). Some mold had been observed during the experiment on the leaves of some Plantago spp. and Erigeron canadensis L. (Asteraceae) suggesting the reduced success rates observed for these species (the lowest ones, 33-54\%) could be attributed to the decay of the tested plants rather than to a rejection of the plants by the nymphs. Only one nymph (10\%) became adult on the strawberry trees (A. unedo) and no adult had been obtained on other shrubs (P. lentiscus) or trees (olive trees). These results confirm that, despites their apparent monophagy on $C$. monspeliensis, the nymphs of the Corsican populations of $P$. spumarius still have the capability of developing on diverse herbaceous species, thus confirming their polyphagy as described in the literature. In Corsica, the specificity of the nymphs and, in spring and autumn, of the adults, can thus not be attributed to a physiological constraint of insular populations. During our field experiments in the Ajaccio region, we noticed that in autumn, when the adults reappeared in the habitat, vegetation of the lowest stratum had not yet been restored. The diversity of turgid plant species was thus limited to a few Mediterranean species, particularly well adapted to the long summer dryness. In the studied area, turgid plants mainly corresponded to C. monspeliensis, by far the most represented species, D. viscosa and some sparse individuals of C. creticus. Most of the foams encountered in early spring were also observed almost exclusively on these 3 species. So it could be argued that when adults came back from their unknown summer shelter to the low vegetation in autumn, there was a limited choice of plant species to feed on. And as these plants appeared to be suitable for the full development of the nymphs, the females did not need to find other species 
432

433

434

435

436

437

438

on which to lay their eggs. We do not know if this observed behaviour is mainly due to climatic constraints on the vegetation or local insect ecological adaptation. Such statement needs complementary studies to be assessed. According to the literature, eggs are often observed on the anfractuosities of dead plant tissues (Weaver \& King, 1954; Cornara et al., 2018). However, such observations took place in cultivated areas such as olive groves or cereal crops, where the vegetation of the lower stratum is not fully restored at the end of summer because of the agricultural practices (labour, pesticides...) and/or the summer conditions. Consequently, no palatable plant is available for the adults when they got back from their summer site, and thus females lay eggs on any suitable substrate in absence of a suitable host plant.

In recent papers dealing with Philaenus species, the host plant, Asphodelus microcarpus, has been synonymised with A. aestivus Brotero, 1804 (Maryańska-Nadachowska et al., 2010; Maryańska-Nadachowska et al., 2012). However, A. aestivus Brot. is restricted to the Central and South-Western parts of the Iberian Peninsula (http://powo.science.kew.org/taxon/5314461), while some of the monophagous Philaenus species (P. signatus and P. italosignus) are not present in this region, suggesting some incoherence in the plant synonymies. A possibility could be that these Philaenus species develop on a different Asphodelus species, whose identification has yet to be determined. Moreover, the microcarpus taxon has been used several times, at different taxonomic levels and associated to several Asphodelus species; incorrect synonymies are thus probable. However, most of the taxa refer to microcarpus Viviani, which is an established synonym of

$A$. ramosus L. (https://wcsp.science.kew.org/synonomy.do?name_id=312417), a species represented in the whole distribution area of the Philaenus species. In this case, A. ramosus L. should be considered as the nymphs host plant of the monophagous Philaenus species. Interestingly, none of the 20 neonate nymphs of Corsican P. spumarius achieves its development on this plant. According to phylogenetic, karyotype and morphological studies, $P$. spumarius belongs to the 
polyphagous or oligophagous "spumarius" group, also including P. tesselatus, P. loukasi and P. arslani; the other Philaenus species belong to the monophagous "signatus" group, including P. signatus, $P$. italosignus, $P$. maghresignus and $P$. tarifa. The shift in the nymph host plant appears to be an important trait closely related to the diversification of the genus Philaenus in Europe. However, it should be interesting to test whether the nymphs of monophagous species could develop on other plant species and reciprocally, but also whether the nymphs of the polyphagous and oligophagous species could accept $A$. ramosus as host plant.

In early spring, foams contained about $1.86 \pm 1.35$ neonate nymphs; this number progressively decreased to $1.08 \pm 0.86$ in early May at the end of the last immature stage, when nymphs were the biggest. Different factors could explain this clutch size decrease, such as the death of the nymphs by predation, parasitism or desiccation. However, such deaths are unlikely because of the presence of the foam within which the nymphs develop and whose role is to protect them against such dangers (Yurtsever, 2000b). Nymphs could also be killed by herbivorous mammals during their food intake, although this scenario is unlikely as Cistus ssp. herbivory has never been observed on the studied site. This observation may result from a behavioural change with neonate nymphs, likely siblings, living together within the same foam and becoming solitary towards the end of their development. It could also be supposed that some nymphs sharing a foam move to create a new one, farther on the same plant or onto a neighbouring plant. This split could be conceivable, as an increase in the proportion of $C$. monspeliensis plants hosting foams ( $26 \%$ vs. $51 \%)$ and in the diversity of plant species with foams (1 species vs. 8 species) was observed between the early March and the end of April in the surveyed transect. Moreover, our experiments demonstrated that despite the nymphs' vulnerability outside the foam, nymphs were able to walk up to $89 \mathrm{~cm}$ in 20 min on a flat surface. A similar capability has been observed in greenhouse conditions, with nymphs moving up to $76 \mathrm{~cm}$ in the vegetation (Weaver \& King, 1954). Finally, a displacement of foams from place to place on the same plant was often 
482

483

484

485

486

487

488

489

490

491

492

493

494

495

496

497

498

499

500

501

502

503

504

505

506

observed overnight (Albre, pers. obs.) or even during the day (Weaver \& King, 1954). Different factors could be implicated in these movements, such as conflicts with congeners within the foam, better access to xylem sap, a decrease in the food quantity/quality or the research for more sheltered sites for the establishment of the foam. Also, the aggregation of some neonate nymphs within the same foam could be an advantage, allowing for the formation of bigger foams, more resistant to drying and providing better protection. These advantages could be reduced or counterbalanced by increased difficulty to access to the xylem sap for bigger nymphs, inducing a behaviour change with their departure/separation and the production of their own new foam.

\section{Conclusions}

We highlighted a strong insect-plant relationship between the nymphs of the meadow spittlebug, Philaenus spumarius, and Cistus monspeliensis in the Ajaccio region of Corsica, probably because this species was the most abundant turgid plant species available in early autumn. In the epidemiological context of the plant pathogen bacterium Xylella fastidiosa, it might be tempting to destroy the central plant host of $P$. spumarius populations, which are the main vector for the bacterium. However, our experiments confirmed that spittlebug nymphs were highly polyphagous on low-growing plant species, as also indicated in the literature. Hence, destroying C. monspeliensis in spring, i.e. when nymphs are developing, could result in a spread of the nymphs towards the neighbouring plants of the low vegetation, as we had observed in several occasions in spring after road banks mowing. Similarly, in absence of $C$. monspeliensis in autumn, it's likely that females of $P$. spumarius may lay their eggs in any dead plant tissues, as described in the literature, resulting in nymphs climbing and developing on any neighbouring turgid low plant species during the next spring. Instead, the strong relationship between $P$. spumarius and $C$. monspeliensis could be used to monitor spittlebug populations, 
507 to limit/concentrate the means of insect control, or in an agronomic context, $C$. monspeliensis

508 could be planted to lure insects away from crops. Unfortunately, the location adult summer

509 habitat remains unknown for the studied population. However, P. spumarius likely move to

510 humid habitats (e.g. riverine vegetation) and/or areas with high densities of turgid trees, making

511 well-watered cultivated groves an ideal habitat for this pathogen vector to seek refuge in

512 Mediterranean climates. Maintaining natural arboreal vegetation around agronomic systems

513 could help decrease insect abundance - and potentially, pathogen load - on cultivated species.

514 Such hypotheses need to be further studied by landscape experiments. 


\section{Acknowledgements}

517 Financial supports were provided to JA by the University of Corsica through its post-doctoral 518 program and the Research Program "Eco-epidemiology of Xylella fastidiosa in Corsica" 519 (Collectivité de Corse - Office de l'Environnement). JMGC is thankful to the Erasmus+ 520 program of the University of Malaga for his stay in Corsica. We are also very grateful to 521 Adrienne Godschalx for her constructive suggestions and the proofreading of the manuscript. 


\section{References}

Albre, J. \& Gibernau, M. (2019) Diversity and temporal variations of the Hemiptera Auchenorrhyncha fauna in the Ajaccio region (France, Corsica). Annales de la Société Entomologique de France (N.S.) 55 (6), 497-508.

Bodino, N., Cavalieri, V., Dongiovanni, C., Plazio, E., Saladini, M.A., Volani, S., Simonetto, A., Fumarola, G., Carolo, M.D., Porcelli, F., Gilioli, G. \& Bosco, D. (2019) Phenology, seasonal abundance and stage-structure of spittlebug (Hemiptera: Aphrophoridae) populations in olive groves in Italy. Scientific Reports 9 (1), 17725.

Borges, P.A.V., Rodrigues, A.S.B., Silva, S.E., Seabra, S.G., Paulo, O.S. \& Quartau, J.A. (2018) New data on polymorphism of the meadow spittlebug Philaenus spumarius (L.) (Hemiptera: Aphrophoridae) from the island of São Miguel (Azores). Zootaxa 4369 (1), 144150.

Chauvel, G., Cruaud, A., Legendre, B., Germain, J.F. \& Rasplus, J.Y. (2015) Mission d'expertise sur Xylella fastidiosa en Corse (3 au 11 août 2015), Ministère de l'agriculture, de l'agroalimentaire et de la forêt (DGAL), Paris, France.

Cornara, D., Bosco, D. \& Fereres, A. (2018) Philaenus spumarius: when an old acquaintance becomes a new threat to European agriculture. Journal of Pest Science 91 (3), 957-972.

Cornara, D., Saponari, M., Zeilinger, A.R., de Stradis, A., Boscia, D., Loconsole, G., Bosco, D., Martelli, G.P., Almeida, R.P.P. \& Porcelli, F. (2017) Spittlebugs as vectors of Xylella fastidiosa in olive orchards in Italy. Journal of Pest Science 90 (2), 521-530. 
Cruaud, A., Gonzalez, A.A., Godefroid, M., Nidelet, S., Streito, J.C., Thuillier, J.M., Rossi, J.P., Santoni, S. \& Rasplus, J.Y. (2018) Using insects to detect, monitor and predict the distribution of Xylella fastidiosa: a case study in Corsica. Scientific Reports 8, 15628.

Dongiovanni, C., Cavalieri, V., Bodino, N., Tauro, D., Di Carolo, M., Fumarola, G., Altamura, G., Lasorella, C. \& Bosco, D. (2019) Plant selection and population trend of spittlebug immatures (Hemiptera: Aphrophoridae) in olive groves of the Apulia region of Italy. Journal of Economic Entomology 112 (1), 67-74.

Drosopoulos, S. (2003) New data on the nature and origin of colour polymorphism in the spittlebug genus Philaenus (Hemiptera: Aphorophoridae). Annales de la Société Entomologique de France (N.S.) 39 (1), 31-42.

Drosopoulos, S. \& Asche, M. (1991) Biosystematic studies on the spittlebug genus Philaenus with the description of a new species. Zoological Journal of the Linnean Society 101 (2), 169177.

Drosopoulos, S., Maryańska-Nadachowska, A. \& Kuznetsova, V.G. (2010) The Mediterranean: area of origin of polymorphism and speciation in the spittlebug Philaenus (Hemiptera, Aphrophoridae). Zoosystematics and Evolution 86 (1), 125-128.

European Food Safety Authority (2018) Update of the Xylella spp. host plant database. EFSA Journal 16(9), e05408.

European and Mediterranean Plant Protection Organization (2013) First report of Xylella fastidiosa in Italy. EPPO Reporting Service 09, 2013/184. 
Halkka, O., Halkka, L., Raatikainen, M. \& Hovinen, R. (1973) The genetic basis of balanced polymorphism in Philaenus (Homoptera). Hereditas 74, 69-80.

Jach, M. (2013) Fauna Europaea: Hemiptera, Cicadomorpha. Fauna Europaea version 2.6.2, available at http://www.faunaeur.org. Accessed March 2020.

Maryańska-Nadachowska, A., Drosopoulos, S., Lachowska, D., Kajtoch, L. \&

Kuznetsova, V.G. (2010) Molecular phylogeny of the Mediterranean species of Philaenus

(Hemiptera: Auchenorrhyncha: Aphrophoridae) using mitochondrial and nuclear DNA sequences. Systematic Entomology 35 (2), 318-328.

Maryańska-Nadachowska, A., Kuznetsova, V.G., Lachowska, D. \& Drosopoulos, S. (2012)

Mediterranean species of the spittlebug genus Philaenus: modes of chromosome evolution. Journal of Insect Science 12 (1), 54.

Masaki, S. (2009) Chapitre 2 - Aestivation pp. 2-4 in Resh, V. H. \& Cardé, R. T. (Eds.) Encyclopedia of insects (second edition). San Diego, CA, USA, Academic Press, Elsevier

\section{Science.}

Morente, M., Cornara, D., Plaza, M., Durán, J., Capiscol, C., Trillo, R., Ruiz, M., Ruz, C., abundance of insect vectors of Xylella fastidiosa in olive groves of the Iberian Peninsula. Insects $9(4), 175$.

600

601 Nickel, H. \& Remane, R. (2002) Artenliste der Zikaden Deutschlands, mit Angaben zu 602 Nährpflanzen, Nahrungsbreite, Lebenszyklen, Areal und Gefährdung (Hemiptera, 603 Fulgoromorpha et Cicadomorpha). Beiträge zur Zikadenkunde 5, 27-64. 
604

605 Richard, E.L.J. (2009) Chapitre 79 - Dormancy pp. 300-301 in Resh, V. H. \& Cardé, R. T. 606 (Eds.) Encyclopedia of insects (second edition). San Diego, CA, USA, Academic Press, 607 Elsevier Science.

608

609 Richards, O.W. \& Davies, R.G. (1977) Hemiptera (Rhynchota: Plant Bugs, Etc.) pp. 679-781

610 in Richards, O. W. \& Davies, R. G. (Eds.) Imms' general textbook of entomology. 10th Ed.

611 Volume 2: Classification and Biology. Lincoln, UK, Chapman \& Hall.

612

613 Rodrigues, A.S.B., Silva, S.E., Pina-Martins, F., Loureiro, J., Castro, M., Gharbi, K., 614 Johnson, K.P., Dietrich, C.H., Borges, P.A.V., Quartau, J.A., Jiggins, C.D., Paulo, O.S. \& 615 Seabra, S.G. (2016) Assessing genotype-phenotype associations in three dorsal colour morphs 616 in the meadow spittlebug Philaenus spumarius (L.) (Hemiptera: Aphrophoridae) using genomic 617 and transcriptomic resources. BMC Genetics 17 (1), 144.

618

619 Santoiemma, G., Tamburini, G., Sanna, F., Mori, N. \& Marini, L. (2019) Landscape 620 composition predicts the distribution of Philaenus spumarius, vector of Xylella fastidiosa, in 621 olive groves. Journal of Pest Science 92 (3), 1101-1109.

622

Saponari, M., Loconsole, G., Cornara, D., Yokomi, R.K., De Stradis, A., Boscia, D., Bosco,

D., Martelli, G.P., Krugner, R. \& Porcelli, F. (2014) Infectivity and transmission of Xylella 625 fastidiosa by Philaenus spumarius (Hemiptera: Aphrophoridae) in Apulia, Italy. Journal of 626 Economic Entomology 107 (4), 1316-1319.

628 Schneider, K., van der Werf, W., Cendoya, M., Mourits, M., Navas-Cortés, J.A., Vicent, 629 A. \& Oude Lansink, A. (2020) Impact of Xylella fastidiosa subspecies pauca in European 630 olives. Proceedings of the National Academy of Sciences 117 (17), 9250-9259. 
632 Shih, H.-T. \& Yang, J.-T. (2002) Checklist of Aphrophoridae (Homoptera: Cercopoidea) from 633 Taiwan. Formosan Entomologist 22, 193-214.

634

635 Stewart, A.J.A. \& Lees, D.C. (1988) Genetic control of colour/pattern polymorphism in 636 British populations of the spittlebug Philaenus spumarius (L.) (Homoptera: Aphrophoridae) 637 Biological Journal of the Linnean Society 34, 57-79.

638

639 Wang, T., Sun, L. \& Chen, M. (2015) Chapitre 11 - Aestivation and regeneration pp. 177-210 640 in Yang, H., Hamel, J.-F. \& Mercier, A. (Eds.) The sea cucumber Apostichopus japonicus. 641 History, biology and aquaculture. Amsterdam, The Netherlands, Academic Press, Elsevier 642 Science.

644 Weaver, C.R. \& King, D.R. (1954) Meadow spittlebug, Philaenus leucophthalmus (L.). Ohio 645 Agricultural Experimental Station Research Bulletin, Wooster, Ohio, USA.

Yurtsever, S. (2000a) Inheritance of the two dorsal colour/pattern phenotypes in New Zealand 648 populations of the polymorphic meadow spittlebug Philaenus spumarius (L.) (Homoptera: 649 Cercopidae). Journal of The Royal Society of New Zealand 30 (4), 411-418.

650

Yurtsever, S. (2000b) On the polymorphic meadow spittlebug, Philaenus spumarius (L.) 652 (Homoptera: Cercopidae). Turkish Journal of Zoology 24 (4), 447-459.

654 Yurtsever, S. (2001) Colour/pattern polymorphism of the meadow spittlebug Philaenus spumarius (Homoptera, Cercopidae) in Northwest Turkey. Biologia 56 (5), 497-501. 
659

660

661

662

663

664

665

666

667

668

669

670

671

672

673

674

675

676

677

678

679

680

681

682

Figure 7. Distribution of the distances travelled by nymphs of $P$. spumarius $(\mathrm{n}=73)$ on a flat paper surface in 20 minutes.

\section{Figure legends}

Figure 1. Cumulative abundance (\%) of Auchenorrhyncha at the studied site near Ajaccio, from March 2017 to December 2019.

Figure 2. Temporal abundance of P. spumarius (black bars) and the other Auchenorrhyncha species (grey shaded curve) at the studied site near Ajaccio, between March 2017 and December 2019 collected twice a month.

Figure 3. Relationship between the number of males and female of $P$. spumarius for the 54 sampled dates between March 2017 and December 2019.

Figure 4. Proportion of adult males of $P$. spumarius captured during different seasons.

Figure 5. Frequency distributions of the plants with foams observed in the studied area. Black histograms: proportion of specimens per species with foams (total number of specimens observed indicated on the top). Grey histograms: distribution of the foams among all the recorded plant species.

Figure 6. Spring temporal variations of the nymphs during their growing season. Empty squares and plain curve: average size of the nymphs' body length (in mm). Black dots and dashed curve: average number of nymphs per foam.

(1) 
684 Tables

685

686 Table 1. Relative abundance of adults of $P$. spumarius collected in the two sampled vegetation 687 strata: low plants (under 120 cm) and higher plants (above $120 \mathrm{~cm}$ ) per semester during the three 688 years of survey.

689

\begin{tabular}{c|c|c|c|c}
\hline \multicolumn{2}{c}{ January - June } & \multicolumn{2}{c}{ July - December } \\
\cline { 2 - 5 } \multicolumn{2}{l|}{ Low plants } & Higher plants & Low plants & Higher plants \\
\hline 2017 & $51.2 \%(22)$ & $48.8 \%(21)$ & $97.3 \%(107)$ & $2.7 \%(3)$ \\
2018 & $76.7 \%(56)$ & $23.3 \%(17)$ & $97.4 \%(264)$ & $2.6 \%(7)$ \\
2019 & $74.4 \%(29)$ & $25.6 \%(10)$ & $96.6 \%(113)$ & $3.4 \%(4)$ \\
\hline Total & 107 & 48 & 484 & 14 \\
\hline
\end{tabular}

690 
691 Table 2. Abundances of the collected Auchenorrhyncha in the various trapping experimental

692 designs soon after the emergence of the adults of $P$. spumarius (end of May - end of June).

693

\begin{tabular}{l|c|c|c}
\hline & $\begin{array}{c}\text { Net-sweeping tree } \\
\text { foliage (6 m high) }\end{array}$ & Yellow sticky traps & $\begin{array}{c}\text { Shaded sticky } \\
\text { shelters }\end{array}$ \\
\hline Philaenus spumarius & $\mathrm{n}=3$ & $\mathrm{n}=0$ & $\mathrm{n}=0$ \\
\hline Other Aphrophoridae & $\mathrm{n}=0$ & $\mathrm{n}=0$ & $\mathrm{n}=0$ \\
\hline Issidae & $\mathrm{n}=7$ & $\mathrm{n}=2$ & $\mathrm{n}=0$ \\
\hline Cicadellidae & $\mathrm{n}=207$ & $\mathrm{n}=252$ & $\mathrm{n}=1$ \\
\hline
\end{tabular}

694

695 
696 Table 3. Evolution of the foam distribution along a $100 \mathrm{~m}$ survey between the March $09^{\text {th }}$ and 697 April 24 ${ }^{\text {th }}$. a. host plant distribution; b. proportion of observed plants for each species with at 698 least one foam.

699

\begin{tabular}{l|cc|ccc}
\hline & \multicolumn{2}{|c|}{$\mathrm{a}$} & \multicolumn{3}{c}{$\mathrm{b}$} \\
& $09 / 03 / 2017$ & $24 / 04 / 2017$ & & & \\
& $\mathrm{n}=33$ foams & $\mathrm{n}=103$ foams & $\mathrm{n}$ plants & & \\
\hline Cistus monspeliensis & $100 \%$ & $86 \%$ & 176 & $26 \%$ & $51 \%$ \\
Cistus creticus & $0 \%$ & $2 \%$ & 22 & $0 \%$ & $10 \%$ \\
Dittrichia viscosa & $0 \%$ & $4 \%$ & 21 & $0 \%$ & $19 \%$ \\
Others (about 15 spp.) & $0 \%$ & $8 \%$ & 111 & $0 \%$ & $19 \%$ \\
\hline
\end{tabular}

700

701 
702 Table 4. Developmental success rate of $P$. spumarius nymphs on different host plant species

703 (listed by alphabetical order). The success rate corresponds to the proportion of nymphs 704 achieving their full development on a bagged leaf ( $\mathrm{N}$ success) out of the initial number of 705 nymphs tested ( $\mathrm{N}$ baggings). *: C. monspeliensis can be considered as a control experimental 706 for the nymph deposition.

707

\begin{tabular}{|c|c|c|c|c|c|}
\hline Family & Species & $\begin{array}{l}\text { Mode of } \\
\text { deposition }\end{array}$ & $\begin{array}{c}\text { N } \\
\text { Baggings }\end{array}$ & $\begin{array}{c}\text { N } \\
\text { success }\end{array}$ & $\begin{array}{c}\text { Success rate } \\
\text { (\%) }\end{array}$ \\
\hline Anacardiaceae & Pistacia lentiscus & Manual & 6 & 0 & $0 \%$ \\
\hline Asteraceae & Anthemis arvensis & Natural & 9 & 9 & $100 \%$ \\
\hline- & Pulicaria odora & Manual & 3 & 3 & $100 \%$ \\
\hline- & Tolpis umbellata & Natural & 2 & 2 & $100 \%$ \\
\hline- & Dittrichia viscosa & Manual & 35 & 26 & $74 \%$ \\
\hline - & Calendula arvensis & Manual & 13 & 9 & $69 \%$ \\
\hline- & Helichrysum italicum & Manual & 9 & 5 & $56 \%$ \\
\hline- & Erigeron canadensis & Manual & 13 & 7 & $54 \%$ \\
\hline Cistaceae & Cistus creticus & Manual & 9 & 9 & $100 \%$ \\
\hline- & Cistus monspeliensis* & Manual & 14 & 14 & $100 \%$ \\
\hline Ericaceae & Arbutus unedo & Manual & 10 & 1 & $10 \%$ \\
\hline Fabaceae & Cytisus laniger & Manual & 12 & 5 & $42 \%$ \\
\hline Liliaceae & Asphodelus ramosus & Manual & 20 & 0 & $0 \%$ \\
\hline Oleaceae & Olea europea & Manual & 12 & 0 & $0 \%$ \\
\hline Plantaginaceae & Plantago coronopus & Natural & 2 & 1 & $50 \%$ \\
\hline- & Plantago lanceolata & Natural & 3 & 1 & $33 \%$ \\
\hline
\end{tabular}

